\title{
Identification and functional characterization of a novel mutation of hepatocyte nuclear factor- $1 \alpha$ gene in a Korean family with MODY3
}

\author{
K.-A. Kim ${ }^{1,2}$, K. Kang1, ${ }^{1,}$, Y.-I. Chi ${ }^{4}$, I. Chang1 ${ }^{1}$, M.-K. Lee ${ }^{1}$, K.-W. Kim ${ }^{1}$, S. E. Shoelson ${ }^{4}$, M.-S. Lee ${ }^{1}$ \\ ${ }^{1}$ Department of Medicine, Samsung Medical Center, Sungkyunkwan University School of Medicine, Kangnam-ku, \\ Seoul, Korea \\ 2 Department of Medicine, MizMedi Hospital, Seoul, Korea \\ ${ }^{3}$ Institute of Biotechnology, Department of Biochemistry, Chungnam National University, Taejon, Korea \\ ${ }^{4}$ Joslin Diabetes Center and Department of Medicine, Harvard Medical School, Boston, MA, USA
}

\section{Abstract}

Aims/hypothesis. After screening 16 Korean families with early onset Type 2 diabetes in search for hepatocyte nuclear factor $(H N F)-1 \alpha$ gene mutation, we identified a novel missense mutation (R263L) associated with MODY phenotype. We studied the biological characteristics of the mutation and the potential functional consequences based on the crystallographic structure of HNF-1 $\alpha$ in complex with DNA.

Methods. DNA from subjects with a familial form of early onset diabetes was isolated and $H N F-1 \alpha$ was sequenced. The R263L substitution was generated by PCR-based sited-directed mutagenesis. Functional and biochemical studies were conducted by reporter assay using glucose-transporter type 2 (GLUT2) or insulin promoters and electrophoretic mobility shift assay, respectively.

Results. Transfection of wild-type HNF-1 $\alpha$ increased the reporter activities of GLUT2 and insulin promoters in NIH3T3 and SK-Hep1 cells, while R263L mutant was defective in transactivation of those promoters. Both wild-type HNF-1 $\alpha$ and R263L mutant could not transactivate GLUT2 and insulin promoters in MIN6N8 insulinoma cells. R263L mutant had a defective cooperation with its heterodimeric partner HNF$1 \beta$ or coactivator $\mathrm{p} 300$. R263L mutant protein displayed greatly reduced DNA binding ability, despite its comparable protein stability to the wild-type HNF-1 $\alpha$. Conclusion/interpretation. These results suggest that the mutation of $H N F-1 \alpha$ at codon 263 from arginine to leucine leads to the development of MODY3 through decreased insulin production and defective glucose sensing. These findings are in good agreement with the crystal structure in which R263 makes hydrogen bonds with phosphorus atoms of DNA backbone to mediate the stable binding of HNF-1 $\alpha$ homeodomain to the promoter. [Diabetologia (2003) 46:721-727]

Keywords MODY, HNF-1 $1 \alpha$, mutation, glucose transporter type 2 , insulin, HNF- $1 \beta$, p300
Received: 15 October 2002 / Revised: 5 February 2003 Published online: 24 April 2003

C) Springer-Verlag 2003

Corresponding author: Dr. M.-S. Lee, Department of Medicine, Samsung Medical Center, Sungkyunkwan University School of Medicine, Irwon-dong 50, Kangnam-ku, Seoul 135710, Korea

E-mail: mslee@smc.samsung.co.kr

Abbreviations: WT, wild-type; HNF, hepatocyte nuclear factor; EMSA, electophoretic mobility shift assay; GST, glutathione S-transferase; PMSF, phenylmethylsulfonyl fluoride; ECL, enhanced chemiluminescence; HA, haemagglutinin; CREB, cAMP-response element-binding protein; CBP, CREB-binding protein.

The first three authors contributed equally to this work
MODY is a heterogeneous form of diabetes characterized by early age of onset, autosomal dominant inheritance and impaired insulin secretion [1]. It has been shown that the third type of MODY (MODY3) results from mutations in the gene encoding hepatocyte nuclear factor (HNF-1 $\alpha)$ [2], a homeodomain-containing transcription factor [3] which is expressed in the liver and pancreatic beta cells $[4,5]$. Defects in $H N F-1 \alpha$ gene are one of the most common causes of MODY in most countries including Asian countries [6, 7].

HNF-1 $\alpha$ forms homodimers or heterodimers with a closely related transcriptional factor, HNF-1 $\beta$, whose mutation also constitutes a form of MODY (MODY5) [8]. Both HNF-1 $\alpha$ and HNF-1 $\beta$ are composed of three 
functional domains: N-terminal dimerization domain, DNA-binding domain and C-terminal transactivation domain. Recent studies disclosed several target genes of HNF- $1 \alpha$ or HNF-1 $\beta$ involved in glucose homeostasis such as L-type pyruvate kinase, glucose transporter type 2 (GLUT2) and insulin genes [9, 10, 11, 12, 13], whose abnormal regulation could lead to impaired insulin synthesis or secretion.

We screened Korean subjects with early onset Type 2 diabetes for $H N F-1 \alpha$ mutations and identified a novel missense mutation CGT $\rightarrow$ CTT, which encodes an R263L substitution. In an attempt to characterize its functional properties, we investigated the effect of R263L mutation on GLUT2 and insulin gene transactivation. Analysis of the crystal structure of human HNF- $1 \alpha$ in complex with DNA provided insights into how this mutation affects function.

\section{Methods}

Subjects and screening of HNF-1 $\alpha$ gene. We studied 16 unrelated Korean subjects with early onset Type 2 diabetes $(<35$ years of age, range 11-35 years) who had first-degree relatives with Type 2 diabetes. Of them five developed diabetes before the age of 25. Genomic DNA was extracted from the whole blood using a genomic DNA extraction kit (Promega, Madison, Wis., USA). PCR amplification of each exon and direct sequencing of the PCR product were carried out according to a previous report [2]. Informed consent was obtained from each subject. The study was approved by the Ethics Committee of Samsung Medical Centre and was carried out in accordance with the Declaration of Helsinki as revised in 2000.

Construction of plasmid. A point mutation (R263L) was introduced to pCMV6b-hHNF-1 $\alpha$, a wild-type (WT) human HNF$1 \alpha$ eukaryotic expression vector [13], using QuickChange Mutagenesis Kit (Stratagene, La Jolla, Calif., USA). The oligonucleotide used for in vitro mutagenesis was $5^{\prime}$-CTCGTCACGGAGGTGCTTGTCTACAACTGGTTTG-3'. The sequence of the mutant was confirmed by direct nucleotide sequencing.

Reporter assay. pGL3-GT2 has a promoter region (nucleotides $-1296 \sim+312$ ) of the human GLUT2 gene cloned into the pGL3-basic vector (Promega) [13]. pGL3-Insulin has a 380-bp fragment of the human insulin promoter $(-362$ to +27 relative to the cap site). In some experiments, HNF-1 $\beta$ or global transcriptional coactivator p300 [14, 15] were transfected together with WT HNF-1 $\alpha$ or its mutant. NIH3T3 fibroblast cells, SKHep1 hepatoma cells and MIN6N8 insulinoma cells (kindly provided by Prof. Jun-ichi Miyagaki, Osaka University, Osaka, Japan) were grown in Dulbecco's Modified Eagle's Medium supplemented with $10 \%$ foetal bovine serum. $5 \times 10^{5}$ cells in each well of the 12-well culture dishes were transfected with $50 \mathrm{ng}$ of WT HNF-1 $\alpha$ (or its mutant) together with $500 \mathrm{ng}$ of a reporter construct and $10 \mathrm{ng}$ of pRL-TK internal control vector (Promega) using Lipofectamine plus Reagent (Life Technologies, Rockville, Md., USA) for 3 h. After another 24 h, cells were lysed and luciferase activity was measured using DualLuciferase Reporter Assay System and Luminometer TD20/20 (Promega).
$X$-ray crystallography. Bipyramidal crystals were grown at room temperature using the hanging drop vapour diffusion method; $2 \mu$ drops containing a mixture of protein $(20-30 \mathrm{mg}$ / $\mathrm{ml}$ ), and DNA (0.6 equivalents) and an equal volume of reservoir solution were equilibrated against $500 \mu \mathrm{l}$ of reservoir solution (100 mmol/l imidazole, $\mathrm{pH} 8.5$, and $30-33 \%$ polyethylene glycol $8 \mathrm{~K}$ ). The structure was analyzed by multiple isomorphous replacement. Heavy atom derivates were prepared by conventional soaking methods or substitution of protein Met residues or DNA thymines with selenomethionine or iodouracil, respectively [16].

Electrophoretic mobility shift assay (EMSA). A prokaryotic expression vector containing R263L mutation was generated from the native glutathione S-transferase (GST)-fusion construct of pGEX4T-1 backbone [16] by using the "mega-primer" method of PCR, and the protein was purified as previously described [16]. Sense and antisense oligos of an HNF-1 $\alpha$ recognition sequence were synthesized and purified as previously described [16]. Annealed 21-mer oligos (5'-CTTGGTTAATAATTCACCAGA-3') were end-labelled using $25 \mu \mathrm{Ci}\left[\gamma_{-}{ }^{32} \mathrm{P}\right]-$ ATP (NEN, Boston, Mass., USA) and $\mathrm{T}_{4}$ polynucleotide kinase (New England Biolabs, Beverly, Mass., USA). The labelled oligonucleotides were purified using Micro Bio-Spin 30 columns (Bio-Rad, Hercules, Calif., USA). Binding reactions were carried out with $5 \mu \mathrm{g}$ of purified proteins in $1 \times$ binding buffer (10 mmol/l Tris-HCl, pH 7.6, 25 mmol/1 NaCl, 1 mmol/l EDTA, 5\% glycerol, $1 \mathrm{mmol} / \mathrm{l}$ dithiothreitol), $750 \mathrm{ng} / \mu \mathrm{l} \mathrm{BSA}$, and $75 \mathrm{ng} / \mu \mathrm{l}$ poly $\mathrm{dI} / \mathrm{dC}$ (Amersham Pharmacia, Uppsala, Sweden) at $4^{\circ} \mathrm{C}$ for $10 \mathrm{~min} .{ }^{32} \mathrm{P}$-labelled oligo $(30,000 \mathrm{cpm})$ was added to the reaction buffer, and samples were incubated at room temperature for $30 \mathrm{~min}$. After adding gel loading buffer, samples were loaded onto $6 \%$ polyacrylamide gel $(25 \mathrm{mmol} / \mathrm{l}$ Tris, $50 \mathrm{mmol} / \mathrm{l}$ glycine, $1 \mathrm{mmol} / 1$ EDTA, $5 \%$ glycerol) in $1 \times$ running buffer $(25 \mathrm{mmol} / \mathrm{l}$ Tris, $50 \mathrm{mmol} / \mathrm{l}$ glycine, $1 \mathrm{mmol} / \mathrm{l}$ EDTA). After electrophoresis for 3 to $4 \mathrm{~h}$ at $150 \mathrm{~V}$, the gel was dried for autoradiography.

Western blot analysis. NIH3T3 cells were transfected with $2 \mu \mathrm{g}$ of pCMV6b-hHNF-1 $\alpha$ or its R263L mutant containing haemagglutinin (HA) tag sequence [13] using Lipofectamine plus Reagent for $3 \mathrm{~h}$. After another $24 \mathrm{~h}$, cells were lysed in a buffer containing $100 \mathrm{mmol} / \mathrm{l} \mathrm{NaCl}, 10 \mathrm{mmol} / \mathrm{l}$ Tris-HCl, pH 7.6, $1 \mathrm{mmol} / \mathrm{l}$ EDTA, $1 \mathrm{mmol} / \mathrm{l}$ phenylmethylsulfonyl fluoride (PMSF) and 1\% NP-40. Protein concentration in cell lysates was measured using a Bio-Rad protein assay kit. After the addition of loading buffer containing $50 \mathrm{mmol} / \mathrm{l}$ Tris- $\mathrm{HCl}$, pH 6.8, 2\% SDS, $8 \%$ glycerol and $0.4 \% \beta$-mercaptoethanol, an equal amount of protein for each sample was separated by $10 \%$ SDS-PAGE and transferred to Hybond enhanced chemiluminescence (ECL) nitrocellulose membranes (Amersham Pharmacia). After blocking with 5\% skimmed milk, the membranes were sequentially incubated with anti-HA antibody (Sigma, St. Louis, Mo., USA) and then horseradish peroxidase-conjugated secondary antibody (Amersham Pharmacia), followed by ECL detection (Amersham Pharmacia).

Statistical analysis. The Student's $t$ test was used to compare the mean relative luciferase unit values between the groups. A $p$ value of less than 0.05 was considered statistically significant. All values were expressed as means \pm SD from an experiment representative of more than three independent experiments done in triplicate, showing a similar tendency. 
A

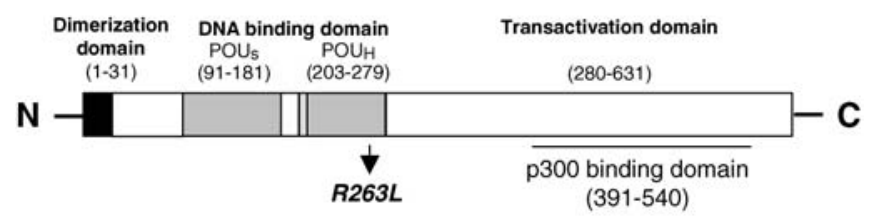

B

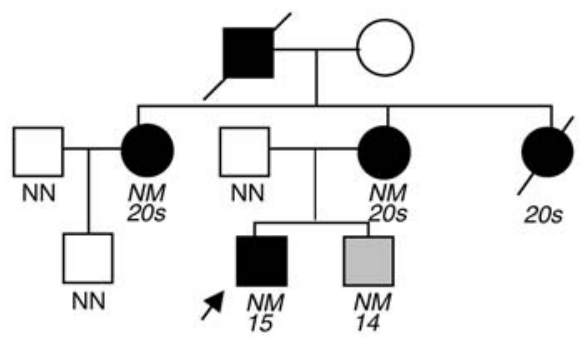

Fig. 1A, B. Schematic representation of HNF-1 $\alpha$ showing functional domains, the relative position of R263L, and region thought to interact with p300. POU $_{\mathrm{S}}$ denotes POU-specific domain and $\mathrm{POU}_{\mathrm{H}}$ denotes homeodomain. B Pedigree of the family with a novel R263L mutation. Subjects with diabetes are indicated by black symbols, without diabetes by white symbols, and with impaired glucose tolerance by a grey symbol. Deceased subjects are indicated by lines drawn through the symbols. Ages at the time of the diagnosis are shown. N, normal; M, mutated (R263L)

\section{Results}

Patients. Among 16 index patients, only one patient had a missense mutation of $H N F-1 \alpha(788 \mathrm{G} \rightarrow \mathrm{T})$, encoding R263L substitution (Fig. 1A). This is a novel mutation in the DNA binding domain of HNF-1 $\alpha$, while change at the same codon from arginine to cysteine (R263C) has been reported in a patient with Type 2 diabetes [7]. The proband in our study was a 16-year-old boy who had a BMI of $18.3 \mathrm{~kg} / \mathrm{m}^{2}$ and was diagnosed with diabetes at the age of 15 . His mother had Type 2 diabetes, and his younger brother had impaired glucose tolerance (Fig. 1B). As his grandfather also had Type 2 diabetes, the clinical diagnosis was consistent with MODY. Genotyping of the affected members of the family showed the same mutation. The index patient had been managed with an oral hypoglycaemic agent for 1 year after diagnosis, and is now being managed with 20 to 28 $\mathrm{U}$ per day of intermediate-acting insulin. His fasting serum C-peptide level was $0.30 \mathrm{nmol} / \mathrm{l}$, which rose to $1.97 \mathrm{nmol} / \mathrm{l} 6 \mathrm{~min}$ after intravenous injection of $1 \mathrm{mg}$ glucagon. Serum C-peptide level during a standard 75-g OGTT was $0.30,1.21$ and $0.99 \mathrm{nmol} / 1$ at 0,30 and $120 \mathrm{~min}$ after glucose intake, while plasma glucose level was $5.1,9.3,14.9,18.2$ and $18.8 \mathrm{mmol} / \mathrm{l}$ at $0,30,60,90$ and 120 min after glucose intake.

Defective activation of GLUT2 and insulin promoters by $R 263 L$ mutant. We first studied the possible functional defects of R263L in terms of transactivation of HNF-1 $\alpha$ target genes. The transactivation of a GLUT2 promoter by R263L mutant was decreased relative to WT HNF$1 \alpha$ in NIH3T3 cells and SK-Hep1 cells (Fig. 2A,B). NIH3T3 cells lack endogenous expression of HNF-1 $\alpha$ whereas SK-Hep1 cells express low levels of the endogenous protein. In contrast, the WT and mutated proteins were equally ineffective in activating GLUT2 promoter in MIN6N8 insulinoma cells (Fig. 2C).

Similar studies were conducted using an insulin promoter, another HNF-1 $\alpha$ target. Transactivation by R263L mutant was decreased compared with WT HNF-1 $\alpha$ in both NIH3T3 and SK-Hep1 cells (Fig. 2D,E). WT and mutant proteins also failed to activate insulin promoter in MIN6N8 cells, similar to GLUT2 promoter (Fig. 2F).

Defective cooperation of $R 263 \mathrm{~L}$ with its heterodimeric partner or coactivator. As HNF-1 $\alpha$ and HNF-1 $\beta$ cooperatively enhance the promoter activity of certain target genes, we expressed WT HNF-1 $\alpha$ or R263L mutant alone or in combination with HNF-1 $\beta$ in NIH3T3 cells and investigated their cooperative effects on GLUT2 promoter. Cotransfection of HNF-1 $\beta$ increased GLUT2 promoter activity compared with WT HNF- $1 \alpha$ transfection alone. HNF-1 $\beta$ cotransfection also increased GLUT2 promoter activity compared with R263L transfection alone. However, the promoter activity after cotransfection of R263L mutant and HNF-1 $\beta$ was still less than that after cotransfection of WT HNF- $1 \alpha$ and $-1 \beta$, suggesting that the overexpression of HNF-1 $\beta$ is able to enhance promoter activity of its heterodimeric partner even in defective forms but R263L mutant still has defects in transactivation of its target genes in cooperation with its partner HNF-1 $\beta$ (Fig. 3A). Similar results were obtained when we used insulin promoter instead of GLUT2 promoter (data not shown).

As p300 has been reported to act as a transcription coactivator for HNF-1 $\alpha$ [17], we next studied whether R263L and p300 could cooperatively enhance GLUT2 promoter activity in NIH3T3 cells that has a low p300 expression. Cotransfection of p300 increased GLUT2 promoter activity compared with WT HNF- $1 \alpha$ transfection alone. p300 cotransfection also increased GLUT2 promoter activity compared with R263L transfection alone. However, the promoter activity after cotransfection of R263L and p300 was still less than that after cotransfection of WT HNF-1 $\alpha$ and p300, suggesting that the overexpression of p300 is able to increase the promoter activity of HNF-1 $\alpha$ even in defective forms but R263L mutant still has defects in transactivation of its target genes in cooperation with coactivator p300 (Fig. 3B).

Structure modelling and biochemical studies of R263L mutant. We analyzed potential effects of the R263L substitution in terms of the recently solved $\mathrm{x}$-ray crystal structure of human HNF-1 $\alpha$ [16]. The 
A
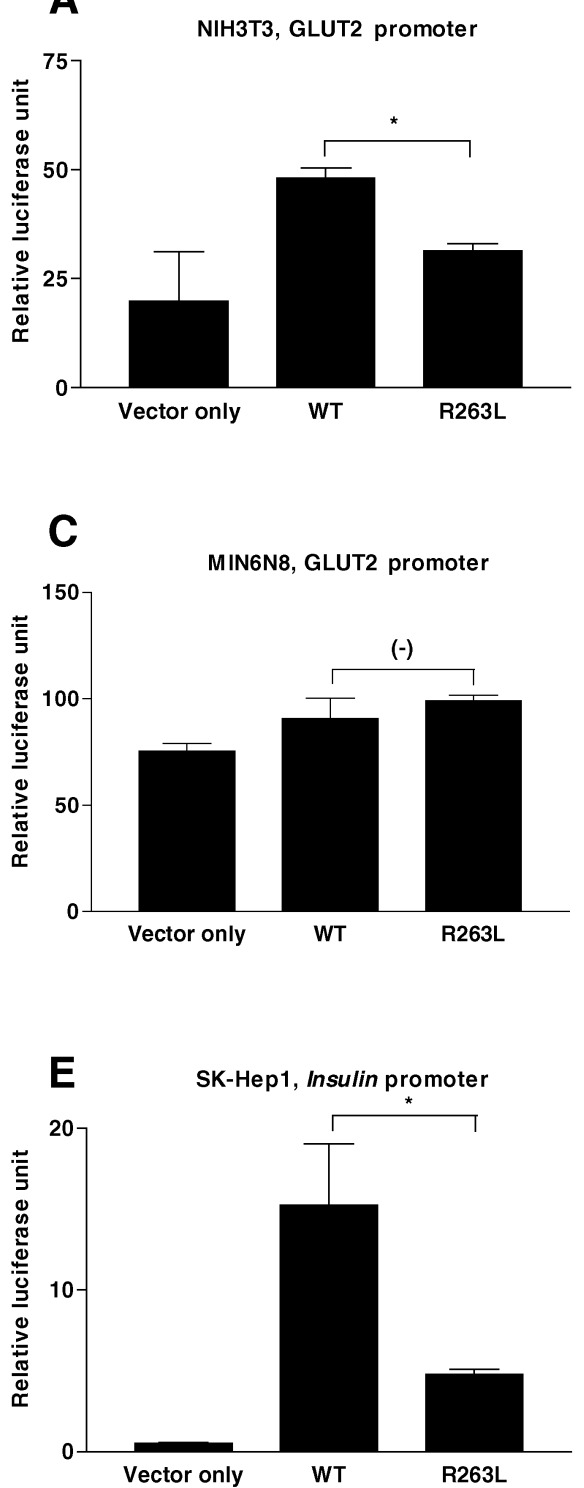

Fig. 2A-F. Defective transcriptional activity of R263L mutant. A, B Expression of R263L induced less transactivation of GLUT2 promoter compared with WT HNF-1 $\alpha$ in NIH3T3 or SK-Hep1 cells. C Neither WT HNF-1 $\alpha$ nor R263L activated GLUT2 promoter in MIN6N8 insulinoma cells. D, E Expression of R263L induced less transactivation of insulin promoter compared with WT in NIH3T3 or SK-Hep1 cells. F Neither WT nor R263L activated the insulin promoter in MIN6N8 insulinoma cells. Results are means $\pm \mathrm{SD}$ of a representative experiment done in triplicate showing similar tendency $[(-), p>0.05 ; *, p<0.01]$

guanidium side chain of R263 interacts with phosphorus atoms of the DNA backbone, directly and through a water molecule, and forms a hydrogen bond with the neighboring residue T260 to stabilize the local environment (Fig. 4). Substitution with leucine, a residue with a neutral and hydrophobic side chain, should disrupt these interactions. As these crystallographic data indicated that the diminished transcriptional activity of $\mathrm{R} 263 \mathrm{~L}$ is due to a decrease in its binding to DNA in the promoters of target genes, we next carried out
B
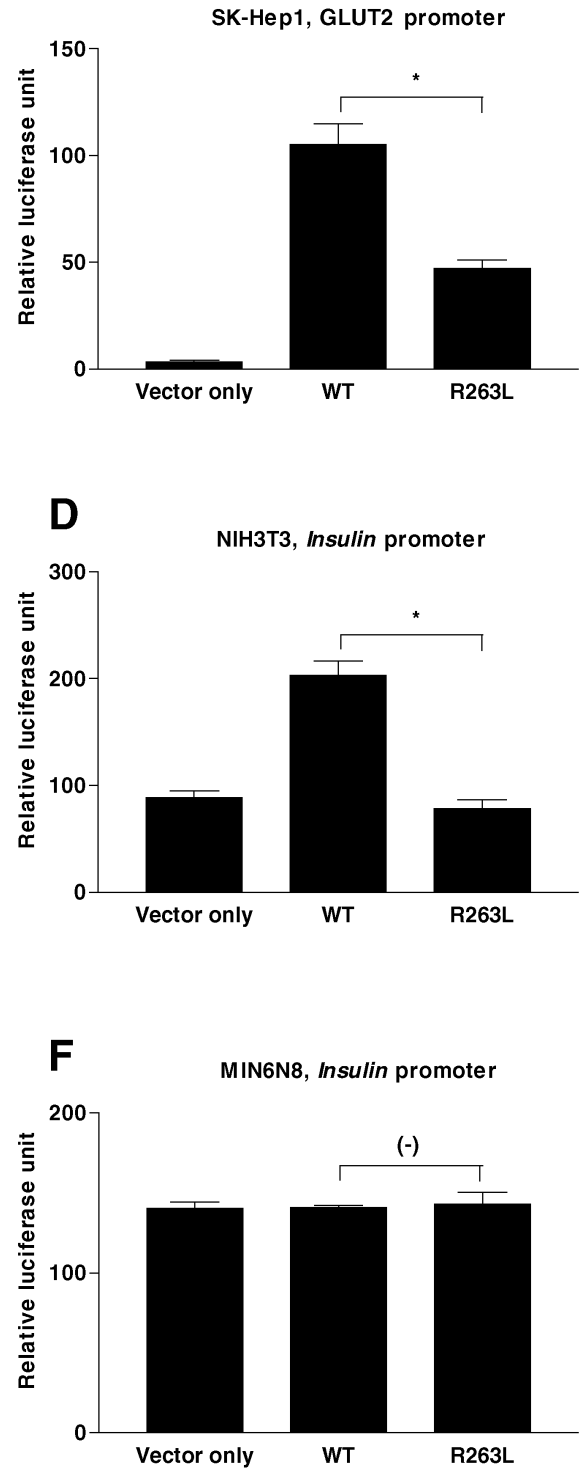

EMSA using the mutant R263L protein. WT HNF-1 $\alpha$ protein retarded the mobility of its recognition sequence, suggesting a good binding to the target promoter sequence. However, R263L mutant protein virtually did not affect migration of the HNF-1 $\alpha$ recognition sequence, indicating its inability to bind to the sequence (Fig. 5A). We next studied the expression level of WT HNF-1 $\alpha$ and R263L mutant proteins because our X-ray crystallographic data suggested potential instability of R263L mutant protein due to the disruption of hydrogen bond between_R263 and T260 and ensuing changes of local environment and recent papers have shown instability of mutant HNF- $1 \alpha$ proteins leading to MODY3 by Western blot analysis [18, 19]. However, Western blot analysis using an antibody to HA tagged to the eukaryotic expression construct disclosed that the expression level of WT HNF-1 $\alpha$ and R263L mutant protein in NIH3T3 cells was similar, suggesting that protein stability is not affected by R263L mutation despite the changes of local environment (Fig. 5B). 


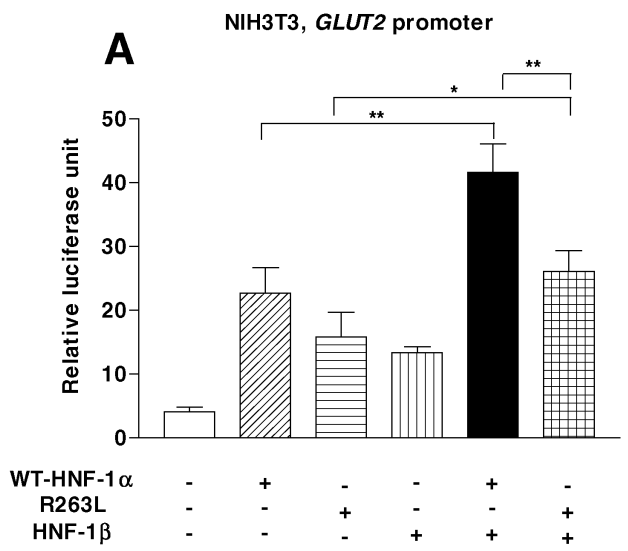

Fig. 3A, B. Defective cooperation of R263L mutant with other transcriptional factors. A Cotransfection of HNF-1 $\beta$ increased GLUT2 promoter activity compared with R263L transfection alone, however, the promoter activity after cotransfection of R263L and HNF-1 $\beta$ was less than that after WT HNF- $1 \alpha$ and $-1 \beta$ cotransfection. B p300 cotransfection increased GLUT2 promoter activity compared with R263L transfection alone, however, the promoter activity after cotransfection of R263L and p300 was still less than that after WT HNF-1 $\alpha$ and p300 cotransfection. Cells were transfected with $500 \mathrm{ng}$ of GLUT2 promoter, $50 \mathrm{ng}$ of HNF-1 $\alpha$ expression vectors and $50 \mathrm{ng}$ of p300 (+) or the empty expression vector $(-)$. Results are means $\pm \mathrm{SD}$ of a representative experiment done in triplicate showing similar tendency $(*, p<0.05 ; * *, p<0.01)$

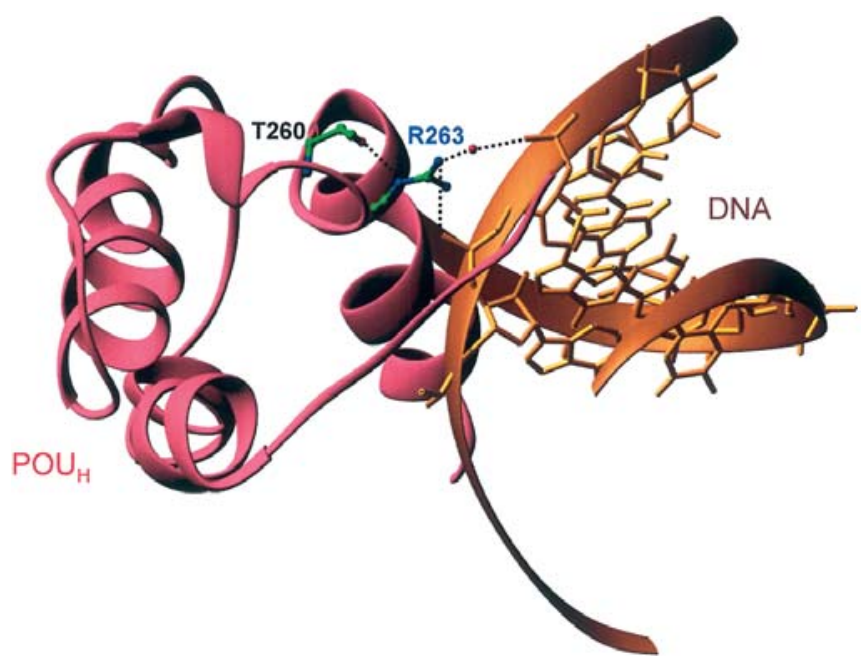

Fig. 4. Detailed structural view of R263 interacting with surrounding residues. HNF-1 $\alpha$ and DNA backbone are represented as ribbons in magenta and gold, respectively. R263 and its hydrogen bonding partners are shown as ball and stick model. For clarity, only homeodomain of HNF-1 $\alpha\left(\mathrm{POU}_{\mathrm{H}}\right)$ is shown. Red dot denotes a water molecule

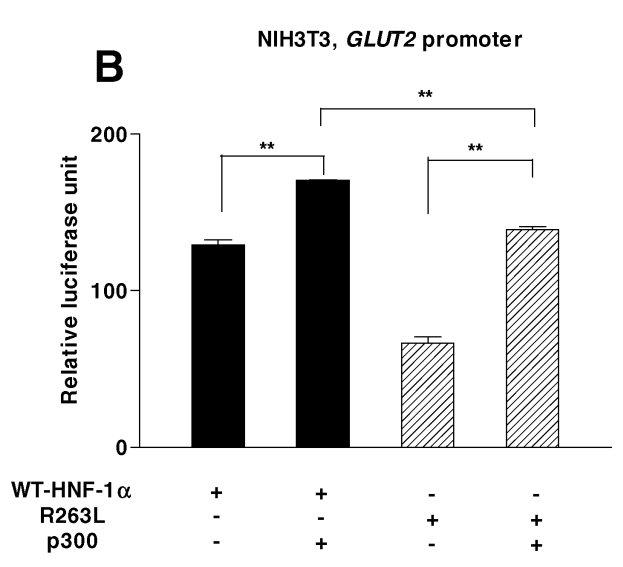

A

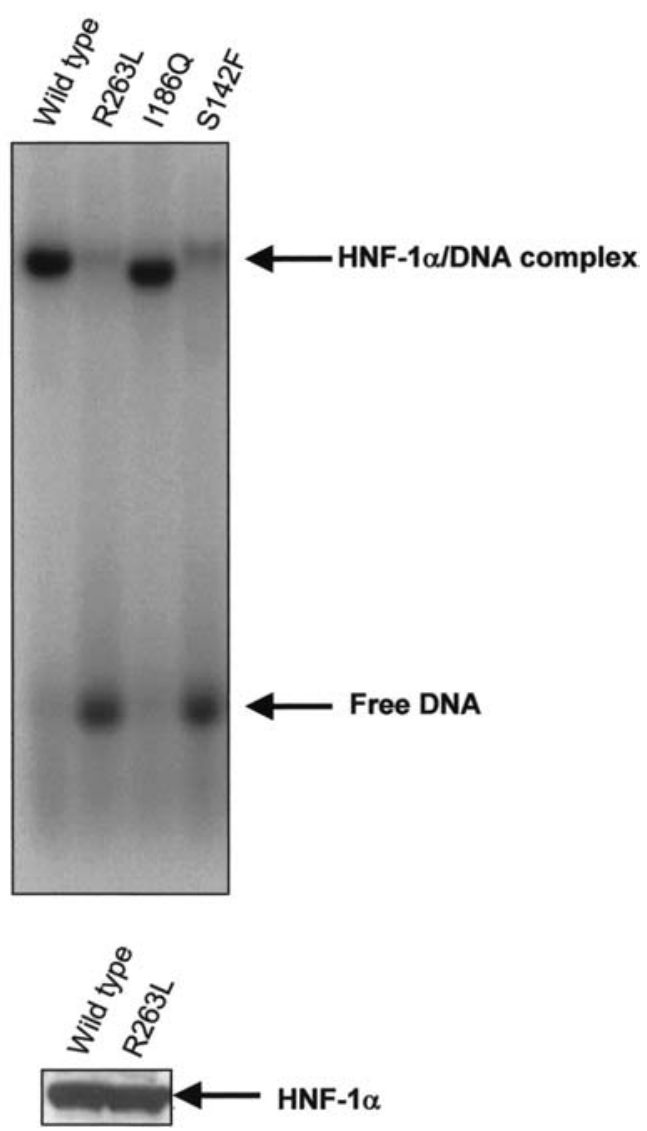

Fig. 5. A EMSA using WT HNF-1 $\alpha$ and mutant proteins. While WT HNF-1 $\alpha$ protein bound well to the HNF- $1 \alpha$ recognition sequence, R263L mutant protein virtually did not bind to the same sequence. A positive control mutant (I186Q) harboring a mutation in the linker between $\mathrm{POU}_{\mathrm{S}}$ and $\mathrm{POU}_{\mathrm{H}}$ domain not related to the DNA binding bound well to the HNF$1 \alpha$ recognition sequence, while a control negative mutation disrupting an extensive hydrogen bonding network with DNA base atoms (S142F) led to disruption of DNA binding. B The expression level of WT HNF-1 $\alpha$ and R263L mutant protein in NIH3T3 cells was similar, suggesting that protein stability is not affected by R263L mutation despite the disruption of local environment between R263 and T260 


\section{Discussion}

In our effort to find MODY3 patients in Korea, we found one family with $H N F-1 \alpha$ mutation. As we did not carry out an extensive search for $H N F-1 \alpha$ mutations in Korean MODY patients, further studies are required to evaluate the prevalence of MODY and its subtypes in our general population.

We showed that the expression of R263L mutant resulted in a decreased activation of human GLUT2 and insulin promoters compared with WT HNF-1 $\alpha$. Similar results were observed using NIH3T3 cells and SK-Hep1 cells. These results are similar to previous reports showing defective transactivation of target gene promoters in $\mathrm{CHO}$ cells and HeLa cells by HNF$1 \alpha$ (R263C), a distinct mutation found in a patient with Type 2 diabetes who does not fulfill the clinical criteria for diagnosis of MODY [7, 20]. Neither the WT nor the R263L mutant activated GLUT2 or insulin promoter in MIN6N8 insulinoma cells, perhaps due to competition with endogenous HNF-1 $\alpha$ in these cells. SK-Hep1 cells also express endogenous HNF$1 \alpha$, but at lower levels, perhaps explaining why GLUT2 and insulin promoters were activated by HNF-1 $\alpha$ in these cells but not the MIN6N8 cells. Furthermore, since MIN6N8 cells express GLUT2 and insulin proteins and SK-Hep1 cells do not, the endogenous promoters in MIN6N8 cells also could compete with transfected reporter constructs. Results showing differential transcriptional activity in distinct cell types suggest that availability of transcriptional cofactors affects the phenotypic characteristics of $H N F-1 \alpha$ mutations. Cells expressing HNF proteins or insulin sensing/producing machinery might not be good host cells for the functional study of MODY mutants.

The crystal structure of HNF-1 $\alpha$ explains why the R263L substitution leads to the defective transactivation of its target gene promoters. Disruption of the specific interaction between the R263 side chain and the promoter DNA backbone would diminish both affinity and specificity between HNF-1 $\alpha$ and DNA, which is compatible with our promoter assays and decreased binding of R263L or R263C mutant to HNF$1 \alpha$ recognition sequences [20]. Disruption of the hydrogen bond between R263 and T260 would destabilize the integrity of the local environment, perhaps further affecting DNA binding. However, destabilization of the integrity of the local environment did not cause instability of HNF- $1 \alpha$ protein as a whole, as suggested by the similar expression level of WT HNF$1 \alpha$ and R263L mutant protein after transfection of NIH3T3 cells.

In our experiment to test cooperative transactivation between HNF- $1 \alpha$ and its heterodimeric partner HNF- $1 \beta$ or coactivator $\mathrm{p} 300$, cotransfection of HNF$1 \beta$ or p300 increased the promoter activity of HNF- $1 \alpha$ target genes compared with HNF-1 $\alpha$ or R263L expression alone. We included global transcriptional co- activator p300 because HNF-1 $\alpha$ has been reported to control chromatin remodelling $[21,22]$ by the recruitment of coactivators possessing intrinsic histone acetytransferase activities such as p300 [23] or its homologue, cAMP-response element-binding protein(CREB)binding protein (CBP) [24]. p300 or CBP also acts as a molecular bridge between transcriptional factors by binding to the activation domain of some transcriptional factors such as CREB as well as multiple components of the basal transcriptional machinery including RNA polymerase II complex [24]. As R263 is not in a region of HNF- $1 \alpha$ interacting with p300 that binds to the transactivation domain of HNF-1 $\alpha$ [17] and HNF- $1 \alpha$ and $-1 \beta$ will interact with each other through their dimerization domains, the R263L mutation should not impair interactions between HNF-1 $\alpha$ and p300 or HNF-1 $\beta$, partly explaining why cotransfection of HNF-1 $\beta$ or p300 increases transcriptional activity of R263L mutant. However, the decreased activity of R263L mutant was not fully rescued by the coexpression with HNF-1 $\beta$ or p300 because R263 in HNF- $1 \alpha$ contacts DNA directly regardless of its binding to HNF-1 $\beta$ or $\mathrm{p} 300$.

While the index patient in this study and most of his family members with R263L mutation have clinically apparent diabetes requiring insulin or an oral hypoglycaemic agent administration, fasting C-peptide level was only in the low normal range and C-peptide responses to glucagon or glucose were not defective. These clinical data are, while consistent with other papers reporting clinical characteristics of MODY3 patients [25], in contrast with our in vitro data showing definitive defects in glucose sensing and insulin production. These discrepancies could be explained by the heterozygous state of the R263L mutation and also by the different availability of other transcriptional factors, coactivators or heterodimeric partners. HNF- $1 \beta$ or $\mathrm{p} 300$ modulates promoter activity of HNF$1 \alpha$ as was shown in this study. In fact, transfection of MIN6N8 insulinoma cells with R263L mutant did not change the activity of insulin or GLUT2 promoter because of endogenous GLUT2 or insulin promoters and HNF proteins. Thus, C-peptide response and clinical profile of the patients with R263L mutation or other mutations of $H N F-1 \alpha$ leading to MODY3 phenotype are modulated by a variety of genetic or environmental factors in addition to the biochemical property of the $H N F-1 \alpha$ mutation itself, leading to variable and subtle phenotypes compared with in vitro biochemical data. Impaired glucose tolerance in a younger brother of the index patient with R263L mutation also supports the role of environmental or other hormonal factors in the development of a phenotype with the same $H N F-1 \alpha$ mutation.

In conclusion, we have identified a novel mutation of $H N F-1 \alpha$ at codon 263 that encoded an arginine to leucine substitution. This mutation found in a Korean MODY family could cause diabetes through defective 
glucose sensing and/or insulin production in pancreatic beta cells because the R263L substitution impairs $\mathrm{HNF}-1 \alpha$ binding to DNA.

Acknowledgements. This work was supported by Science Research Centre Grants from the Korea Science \& Engineering Foundation and Health Planning Technology \& Evaluation Board Grants (02-PJ1-PG1-CH04-0001) (M.-S.L.). This work was also supported by NIH grant R01 DK43123 (S.E.S.) and a fellowship from the Mary K. Iacocca Foundation (Y.-I.C.). M.-S. Lee is an awardee of the National Research Laboratory Grants from the Korea Institute of Science \& Technology Evaluation and Planning (2000-N-NL-01-C-232). We thank Dr. J. Takeda (Gunma University) for generously providing human HNF-1 $\alpha$ expression vector (pCMV6b-hHNF-1 $\alpha$ ), HNF-1 $\beta$ expression vector and pGL3-GT2. We are also grateful to Dr. K. Yamagata (Osaka University) for providing pGL3-Insulin construct and Dr. J.W. Lee (Pohang University of Science and Technology, Pohang, Korea) for providing p300. We are indebted to Dr. M.S. Nam for helpful discussion and Dr. B.-C. Oh for the production of R263L mutant construct.

\section{References}

1. Fajans SS (1989) Maturity-onset diabetes of the young (MODY). Diabetes Metab Rev 5:579-606

2. Yamagata K, Oda N, Kaisaki PJ et al. (1996) Mutations in the hepatocyte nuclear factor-1alpha gene in maturity-onset diabetes of the young (MODY3). Nature 384:455-458

3. Frain M, Swart G, Monaci P et al. (1989) The liver-specific transcription factor LF-B1 contains a highly diverged homeobox DNA binding domain. Cell 59:145-157

4. Mendel DB, Crabtree GR (1991) HNF-1, a member of a novel class of dimerizing homeodomain proteins. J Biol Chem 266:677-680

5. Tronche F, Yaniv M (1992) HNF1, a homeoprotein member of the hepatic transcription regulatory network. Bioessays 14:579-587

6. Frayling TM, Evans JC, Bulman MP et al. (2001) Beta-cell genes and diabetes: molecular and clinical characterization of mutations in transcription factors. Diabetes 50 [Suppl 1]:S94-S100

7. Iwasaki N, Oda N, Ogata M et al. (1997) Mutations in the hepatocyte nuclear factor-1alpha/MODY3 gene in Japanese subjects with early- and late-onset NIDDM. Diabetes 46:1504-1508

8. Horikawa Y, Iwasaki N, Hara M et al. (1997) Mutation in hepatocyte nuclear factor- $1 \beta$ gene (TCF2) associated with MODY. Nat Genet 17:384-385

9. Yamagata K, Yang Q, Yamamoto K et al. (1998) Mutation $\mathrm{P} 291 \mathrm{fsinsC}$ in the transcription factor hepatocyte nuclear factor-1alpha is dominant negative. Diabetes 47:1231-1235

10. Wang H, Maechler P, Hagenfeldt KA, Wollheim CB (1998) Dominant-negative suppression of HNF-1alpha function results in defective insulin gene transcription and impaired metabolism-secretion coupling in a pancreatic beta-cell line. EMBO J 17:6701-6713

11. Tomura H, Nishigori H, Sho K, Yamagata K, Inoue I, Takeda J (1999) Loss-of-function and dominant-negative mechanisms associated with hepatocyte nuclear factor1beta mutations in familial type 2 diabetes mellitus. J Biol Chem 274:12975-12978

12. Okita K, Yang Q, Yamagata K et al. (1999) Human insulin gene is a target gene of hepatocyte nuclear factor-1alpha (HNF-1alpha) and HNF-1beta. Biochem Biophys Res Commun 263:566-569

13. Yamada S, Tomura H, Nishigori H et al. (1999) Identification of mutations in the hepatocyte nuclear factor-1alpha gene in Japanese subjects with early-onset NIDDM and functional analysis of the mutant proteins. Diabetes 48:645-648

14. Na SY, Lee SK, Han SJ, Choi HS, Im SY, Lee JW (1998) Steroid receptor coactivator-1 interacts with the p50 subunit and coactivates nuclear factor kappaB-mediated transactivations. J Biol Chem 273:10831-10834

15. Arany Z, Sellers WR, Livingston DM, Eckner R (1994) E1A-associated p300 and CREB-associated CBP belong to a conserved family of coactivators. Cell 77:799-800

16. Chi YI, Frantz JD, Oh BC, Hansen L, Dhe-Paganon S, Shoelson SE (2002) Diabetes mutations delineate an atypical POU domain in HNF-1alpha. Mol Cell 10:1129-1137

17. Ban N, Yamada Y, Someya Y et al. (2002) Hepatocyte nuclear factor-1alpha recruits the transcriptional co-activator p300 on the GLUT2 gene promoter. Diabetes 51:1409-1418

18. Vaxillaire M, Abderrahmani A, Boutin P et al. (1999) Anatomy of a homeoprotein revealed by the analysis of human MODY3 mutations. J Biol Chem 274:35639-35646

19. Yoshiuchi I, Yamagata K, Yoshimoto M et al. (2001) Analysis of a non-functional HNF-1alpha (TCF1) mutation in Japanese subjects with familial type 1 diabetes. Hum Mutat 18:345-351

20. Yang Q, Yamagata K, Yamamoto K et al. (1999) Structure/function studies of hepatocyte nuclear factor-1alpha, a diabetes-associated transcription factor. Biochem Biophys Res Commun 266:196-202

21. Pontoglio M, Faust DM, Doyen A, Yaniv M, Weiss MC (1997) Hepatocyte nuclear factor 1alpha gene inactivation impairs chromatin remodeling and demethylation of the phenylalanine hydroxylase gene. Mol Cell Biol 17:4948-4956

22. Rollini P, Fournier RE (1999) The HNF-4/HNF-1alpha transactivation cascade regulates gene activity and chromatin structure of the human serine protease inhibitor gene cluster at 14q32.1. Proc Natl Acad Sci USA 96:10308-10313

23. Lundblad JR, Kwok RP, Laurance ME, Harter ML, Goodman RH (1995) Adenoviral E1A-associated protein p300 as a functional homologue of the transcriptional co-activator CBP. Nature 374:85-88

24. Kwok RP, Lundblad JR, Chrivia JC et al. (1994) Nuclear protein $\mathrm{CBP}$ is a coactivator for the transcription factor CREB. Nature 370:223-226

25. Fajans SS, Bell GI, Polonsky KS (2001) Molecular mechanisms and clinical pathophysiology of maturity-onset diabetes of the young. N Engl J Med 345:971-980 